\section{Correlation between the preoperative state of nutrition and the frequency of postoperative problems after video-assisted gastrostomy in children}

\section{Torbjörn Backman, Helen Sjövie, Carl-Magnus Kullendorff, Einar Ólafur Arnbjörnsson}

Department of Pediatric Surgery, University Hospital, Lund, Sweden

\section{Abstract}

Gastrostomy operations are performed on children referred to the pediatric surgical clinic without being influenced by the patient's state of nutrition. This has been motivated by the idea that a gastrostomy would enable a fast and secure improvement in this regard. The question arises whether an improvement in the preoperative nutritional status would reduce the number of postoperative complications. The aim of the study was to test the hypothesis that the frequency of postoperative complications after a video-assisted gastrostomy is correlated to the child's preoperative state of nutrition. Fifty consecutive children with severe nutritional problems underwent a video-assisted gastrostomy operation where gastrostomy buttons were placed as the initial surgical feeding tube. At the time of the operation, the children's nutritional parameters were registered routinely. After the operation, the children were followed up prospectively for six months and all complications were documented according to a protocol. The children were ranked according to the severity and frequency of postoperative complications and problems. Correlation to nutritional parameters was calculated. The children did not present with any serious postoperative intraabdominal complications. There was a significant correlation between the frequency of minor complications and the child's state of nutrition, measured as the number of standard deviations from normal length and weight as well as phosphate, magnesium, and iron levels in the blood. This study revealed a significant correlation between the patients' state of nutrition and the postoperative complications during the first postoperative six months. Thus, the findings support a routine of nutritional evaluation prior to performing a gastrostomy operation.

\section{Introduction}

The placement of gastrostomy tubes to provide direct access for enteric feeding is an alternative to a nasogastric tube in infants and children who are unable to manage normal oral feeding for a long time and in whom the nasogastric tube causes respiratory or other problems. Different operative procedures have been described, including the time-honored open surgical methods and the more recently introduced minimal invasive methods for gastrostomy: percutaneous endoscopic gastrostomy (PEG) ${ }^{1}$ and video-assisted gastrostomy (VAG). ${ }^{2}$ In order to avoid the complications associated with $\mathrm{PEG}^{3}$ the laparoscopy or VAG technique has been developed and used at our center since $1993 .^{4 \cdot 7}$

Until now, we have been performing gastrostomy operations on patients referred to the pediatric surgical clinic without any influence of the results of the routine evaluation of the nutritional status of the patient. This has been motivated by the idea that a gastrostomy would enable a fast and secure improvement in this regard. The question arises whether an improvement in the preoperative nutritional status would reduce the number of postoperative complications. In this study, we prospectively register the routinely performed evaluation of the nutritional status of the patients, perform a gastrostomy operation, and follow the patients according to a protocol. The occurrence of postoperative complications is correlated to the patients' nutritional status at operation. The hypothesis is that the better the patients' preoperative nutritional status, the fewer the postoperative complications.

The aim of this project was to obtain information that can be used to improve our practice when performing gastrostomy operations in children, thus improving the quality of our work as well as the safety when performing a gastrostomy operation in cases where it is needed. We are not aware of any other similar reports in the literature.

\section{Materials and Methods}

A gastrostomy button was placed consecutively in a heterogeneous sample of 50 children with nutritional problems using a standardized video-assisted, laparoscopic, technique ${ }^{4,7}$ during the period from January 2006 through 2008. We used a MicKey® gastrostomy button type (provided by Ballard Medical Product, Draper, UT, USA). The size and length of the button are summarized in Table 1. The demographic data of all the children are summarized in Table 1 and their diagnoses in Table 2. There was no selection of patients. All those
Correspondence: Torbjörn Backman, Department of Pediatric Surgery, University Hospital, SE-221 85 Lund, Sweden. E-mail: torbjorn.backman@skane.se

Acknowledgments: Gillian Sjödahl, Lexis English for Writers, Persikevägen 11, 22355 Lund Sweden, for linguistic revision of the manuscript; Håkan Lövkvist MSC, biostatistician, Competence Centre for Clinical Research, University Hospital, SE-221 85 Lund, Sweden, for statistical advice.

Contributions: all authors made substantial contributions to conception and design of the study; to acquisition, analysis, and interpretation of data; to drafting, critically revising, and approval of the manuscript.

Conflict of interest: the authors guarantee that the manuscript will not be published elsewhere in any language without the consent of the copyright owners, that the rights of third parties will not be violated, and that the publisher will not be held legally responsible should there be any claims for compensation. This study complies with the current laws of the country in which it was performed.

Received for publication: 27 June 2009 .

Accepted for publication: 29 August 2009.

This work is licensed under a Creative Commons Attribution 3.0 License (by-nc 3.0).

(C) Copyright T. Backman et al., 2009 Licensee PAGEPress, Italy

Gastroenterology Insights 2009; 1:e2 doi:10.4081/gi.2009.e2

who were operated on with a video-assisted gastrostomy during the period are included in the study.

The indication for a gastrostomy was severe nutrition problems in the child and when nutritional support was considered necessary for more than six months. The operation was carried out when the child's condition would safely allow surgical intervention. The gastrostomy operation was never performed prophylactically. Before the gastrostomy button placement, all the children were clinically evaluated for gastroesophageal reflux and gastric emptying. An upper GI X-ray and a 24-hr pH measurement in the esophagus were performed when considered necessary. We used a wireless technique, the Bravo ${ }^{\mathrm{TM}} \mathrm{pH}$-system (Medtronic, Shoreview, MN, USA), which is a radio-transmitted capsule for esophageal pH-monitoring in 16 out of the 50 children. The results are summarized in Table 1. The children's symptoms were not considered to motivate an operative intervention with a fundoplication.

Gastroscopy was performed in all patients at the same time as the gastrostomy was per- 
Table 1. Summary of the demographic data of children included in the study.

\begin{tabular}{ll}
\hline Parameters & Data \\
Number of children (male/female) & $50(31 / 19)$ \\
Age, years (mean \pm SD) & $2.8 \pm 3.1$ \\
Median (range) & $1.6(0.1-12)$ \\
\hline Body weight, kg (mean \pm SD) & $11.5 \pm 6.0$ \\
Median (range) & $9.1(4-35)$ \\
Z-score* for weight (range) & $-2.2 \pm 1.8(-7.1-1.3)$ \\
Body length, cm (mean \pm SD) & $82 \pm 23$ \\
Medan (range) & $74(55-139)$ \\
Z-score* for length (range) & $-1.7 \pm 1.5(-5.8-0.9)$ \\
\hline
\end{tabular}

Results of pH-monitoring during 24 hours, mean value

(time/No. of reflux/scores) and range (in parentheses)

$\%$ time $\mathrm{pH}<4$

No. of reflux episodes

No. of reflux episodes $\geq 5 \mathrm{~min}$

Longest reflux episode, min

DeMeester score**

$42(0-156)$

$1(0-9)$

$7(0-22)$

$12(1-40)$

Gastrostomy button

Size: 12 French/14 French in

Length: $1 \mathrm{~cm} / 1.5 \mathrm{~cm}$ in

$7 / 43$ children

$13 / 37$ children

During the first postoperative month

Increased in weight

Decreased in weight

Unchanged

Died

$43(86 \%)$
$2(4 \%)$
$5(10 \%)$
0

* Z-scores are calculated as (actual weight - mean weight)/standard deviation ${ }^{8}$ according to the national standardized weight curves. ${ }^{* * * 95^{\text {th }}}$ percentile $<14.72$.
Table 2. Diagnoses of the fifty children included in the study.

Number of children

50

\begin{tabular}{ll} 
Diagnosis & \\
Cerebral palsy & $26(52 \%)$ \\
Malignancy & $4(8 \%)$ \\
Cardiac anomaly & $7(14 \%)$ \\
Metabolic disease and syndrome & $10(20 \%)$ \\
Gastrointestinal malformations & $3(6 \%)$ \\
\hline
\end{tabular}

Table 3. Summary of the number and type of complications occurring during the first postoperative six months in the patients included in the study.

$\begin{array}{ll} & \begin{array}{l}\text { Number of } \\ \text { patients }(\mathrm{N}=50)\end{array} \\ \begin{array}{l}\text { Complications during } \\ \text { the first six postoperative } \\ \text { months: } \\ \text { Infection, } \\ \text { antibiotics used } \\ \text { Granuloma around } \\ \text { the gastrostoma }\end{array} & 12(24 \%) \\ \text { Leakage } & 15(30 \%) \\ \end{array}$

formed. At that time none of the patients had esophagitis. A gastric emptying scan or measure of impedance was not performed. In the present study, no patient had clinical signs of intra-abdominal infection, and none were being treated with cytostatic drugs or steroid medication at the time of surgery.

A routine preoperative evaluation of the children's nutritional status was performed including laboratory tests, as listed in Table 4, as well as weight and length. We used the ageadjusted Z-score of weight and length to normalize the data relative to a reference population. These figures are expressed as weightfor-age Z-scores calculated as: actual weightmean weight/standard deviation, ${ }^{8}$ according to the nationally standardized weight curves. ${ }^{9}$

All the children were prospectively followed up by a specially trained nurse during the first postoperative days in hospital and at one and six months after the operation, and any time the child's guardians felt the need for help or advice. All postoperative complications were documented according to a special protocol including only those requiring treatment. These included:

Severe complications

- Complications demanding emergency reoperations, including bleeding, gastrointestinal fistula, or intestinal obstruction. Minor complications
Table 4. Nutritional parameters correlated to the rank order of the 50 patients included in the study.

\begin{tabular}{lllr}
\hline $\begin{array}{l}\text { Parameters measured } \\
\text { (Reference value) }\end{array}$ & $\begin{array}{l}\text { Findings } \\
\text { Median (range) }\end{array}$ & $\begin{array}{c}\text { Correlation } \\
\text { Coefficient }\end{array}$ & $\begin{array}{c}\text { Statistics } \\
p\end{array}$ \\
Age, years & $1.6(0.1-14)$ & 0.089 & 0.539 \\
Weight, kg & $9.1(4.1-41)$ & -0.125 & 0.386 \\
\hline Z-score for weight & $-2.3(-7.1-1.3)$ & -0.518 & $<0.001^{*}$ \\
Length, cm & $74(56-147)$ & -0.018 & 0.902 \\
\hline Z-score for length & $-1.9(-5.8-0.9)$ & -0.515 & $<0.001^{*}$ \\
B-Haemoglobin $(100-150 \mathrm{~g} / \mathrm{L})$ & $121(88-148)$ & -0.036 & 0.803 \\
\hline MCV $(80-94 \mathrm{fL})$ & $81(62-91)$ & -0.088 & 0.544 \\
Serum iron $(10-30 \mu \mathrm{mol} / \mathrm{L})$ & $9(4-17)$ & -0.307 & $0.029 *$ \\
\hline P-TIBC $(51-86 \mu \mathrm{mol} / \mathrm{L})$ & $51(9-77)$ & 0.014 & 0.923 \\
C-reactive protein $(<5 \mathrm{mg} / \mathrm{L})$ & $6.5(0.8-52)$ & 0.139 & 0.335 \\
\hline S-Albumin $(35-48 \mathrm{~g} / \mathrm{L})$ & $32(21-50)$ & -0.229 & 0.110 \\
S-Sodium $(132-145 \mathrm{mmol} / \mathrm{L})$ & $138(132-145)$ & -0.129 & 0.372 \\
\hline S-Potassium $(3.6-4.6 \mathrm{mmol} / \mathrm{L})$ & $4.2(2.8-5.9)$ & -0.029 & 0.839 \\
S-Calcium $(1.7-3.0 \mathrm{mmol} / \mathrm{L})$ & $2.2(1.6-2.6)$ & -0.132 & 0.362 \\
\hline S Ionized calcium $(1.2-1.4 \mathrm{mmol} / \mathrm{L})$ & $1.3(1.1-2.4)$ & -0.002 & 0.987 \\
S-Urea $(1.7-7.3 \mathrm{mmol} / \mathrm{L})$ & $2.4(0.7-6.5)$ & -0.078 & 0.589 \\
\hline S-Creatine $(14-37 \mathrm{mmol} / \mathrm{L}$ & $17(5.0-48)$ & -0.165 & 0.252 \\
S-Phosphorus $(1.5-2.1 \mathrm{mmol} / \mathrm{L})$ & $1.4(1.1-2.5)$ & -0.367 & $0.009 *$ \\
\hline S-Magnesium $(0.7-1.1 \mathrm{mmol} / \mathrm{L})$ & $0.8(0.5-1.2)$ & -0.287 & $0.043^{*}$ \\
\hline Statisticaly signiflcat. & & & \\
\hline
\end{tabular}

*Statistically significant.

- Infectious complications treated with antibithe wound. otics and frequent changes of dressing of - Granuloma treated with cauterization or 
operative intervention.

- Leakage, which was taken care of by increasing the volume in the balloon of the gastrostomy button, or a change to a longer or shorter device in the gastrostoma.

- Pain around the gastrostoma after the first two postoperative days, treated with analgesics.

- Any discomfort leading to the change of device in the gastrostomy.

- The number of parents' consultations for the child's gastrostomy.

The children were ranked according to the frequency and severity of these postoperative problems up to six months after the gastrostomy operation, which was the endpoint of the study. An approval by our hospital Institutional Review Board for the study protocol was not required because our group changed policy and transitioned from older procedures to the new technique under the study period. This study included only a conventional follow-up of the routinely operated patients. As the protocol was designed to meet the legislative documentation required in the country of origin, no formal approval from the ethical committee was necessary and not sought. The verbally informed consent of the children's guardians was obtained, and this was carried out in accordance with the ethical standards laid down in the 1964 Declaration of Helsinki.

\section{Statistical considerations}

Based on our previously published data using the frequency of postoperative complications as the primary endpoint, a sample size of 50 patients was calculated to be sufficient to perform a correlation test at a power of $80 \%$. The nonparametric Spearman's two-tail test was used. All statistical computations were made using SPSS version 15 (SPSS, Inc., Chicago, IL, USA). A $p<0.05$ was considered significant.

\section{Results}

All the buttons were successfully placed using the video-assisted technique without any intraoperative complications. There were no serious complications during the period studied. The postoperative complications are summarized in Table 3 , and include wound infections, granuloma, and leakage. These postoperative complications were used to rank the patients according to their severity and frequency. The results were correlated with the findings of the registration of the nutrition parameters, summarized in Table 4. There is a significant correlation between the frequency of postoperative problems and the low Z-score for weight and length as well as for low phosphate, magnesium, and iron levels in the blood at the time of the operation.

\section{Discussion}

There is a notion that the better the nutritional state of the patient the fewer the postoperative complications, and these are easier to deal with during the postoperative period. The results presented here support the necessity of preoperative nutrition evaluation and treatment before a video-assisted gastrostomy operation. These findings are influenced by the fact that the children included had already had a period of treatment and care, and been given a sufficient amount of nutrition through a nasogastric tube or intravenous nutritional support.

The diet anamnesis was intended to be included. However, when this was to be registered, we discovered that the dietitian had met the patient already and for a while administered the amount of nutrition considered necessary for the child's age and weight. The children under one year of age usually received $100-120 \mathrm{kcal} / \mathrm{kg} /$ day. The older children received Kcal according to the formula: $\mathrm{Kcal} / \mathrm{kg} /$ day $=95-(3 \mathrm{x}$ age in years $)$, or more when considered necessary. Thus the children's problems were failure to thrive owing to complex medical issues and not malnutrition. Therefore, this parameter could not be used. Postoperatively, no changes were made in the amount of nutrition the child had been given preoperatively.

Preoperatively, all the children had had a nasogastric tube for feeding while waiting for the operative intervention that provided the child with a gastrostomy. The latter took place within six weeks from the time when the decision to operate was taken. In spite of this treatment, the difference in the children's nutritional status correlated with the frequency and severity of the postoperative complications.

The preoperative intake of nutrition was considered sufficient for the child's age and weight in all the patients, and took into account the increased need seen in some patient groups; that is, children with congenital cardiac anomalies who are in need of up to $40 \%$ more nutrition than other children of same age and weight. Therefore the Z-scores used here are not any direct marker of malnutrition, but are more reflective of failure to thrive.

During the period studied we had no children with tracheostomies. These children are well known to have considerable problems with their gastrostomies owing to an increased abdominal pressure because of increased work of breathing leading to an increased leaking around the gastrostomy tube.

The rate of serious complications in this group of patients is lower than that previous- ly reported for PEG or standard Stamm gastrostomies, which is as high as $40 \% .{ }^{10}$ The most serious complications were wound infections that, in this series of patients, were resolved with oral antibiotics or a frequent change of dressing only.

In conclusion, this study revealed a significant correlation between the patients' state of nutrition and the postoperative complications during the first six postoperative months. Thus, the findings substantiate a routine of nutritional evaluation and support prior to performing a gastrostomy operation.

\section{References}

1. Gauderer MWL. Percutaneous endoscopic gastrostomy: a 10-year experience with 220 children. J Pediatr Surg 1991;26:28894.

2. Aprahamian CJ, Morgan TL, Harmon CM, et al. U-stitch laparoscopic gastrostomy technique has a low rate of complications and allows primary button placement: experience with 461 pediatric procedures. J Laparoendosc Adv Surg Tech A 2006;16: 643-9.

3. Patwardhan N, McHugh K, Drake D, et al. Gastroenteric fistula complicating percutaneous endoscopic gastrostomy. J Pediatr Surg 2004;39:561-4.

4. Backman T, Arnbjornsson E, Berglund Y, et al. Video-assisted gastrostomy in infants less than 1 year. Pediatr Surg Int 2006;22: 243-6.

5. Noren E, Gunnarsdottir A, Hanseus K, et al. Laparoscopic gastrostomy in children with congenital heart disease. J Laparoendosc Adv Surg Tech A 2007; 17:483-9.

6. Arnbjornsson E, Backman T, Morse H, et al. Complications of video-assisted gastrostomy in children with malignancies or neurological diseases. Acta Paediatr 2006;95: 467-70.

7. Jones VS, La Hei ER, Shun A. Laparoscopic gastrostomy: the preferred method of gastrostomy in children. Pediatr Surg Int 2007;23:1085-9.

8. Liou TG, Adler FR, Fitzsimmons SC, et al. Predictive 5-year survivorship model of cystic fibrosis. Am J Epidemiol 2001;53: 345-52.

9. Albertsson-Wikland K, Karlberg J. Natural growth in children born small for gestational age with and without catchup growth. Acta Paediatr Suppl 1994;399:6470.

10. Rothenberg SS, Bealer JF, Chang JH. Primary laparoscopic placement of gastrostomy buttons for feeding tubes. A safer and simpler technique. Surg Endosc 1999; 13:995-7. 